\title{
Evaluation of the Effect of the Inspired Oxygen Fraction on Blood Oxygenation during Inhalant Anaesthesia in Horses: A Systematic Review with Meta-Analysis
}

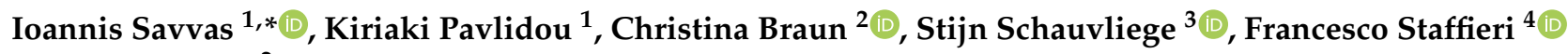 \\ and Yves Moens ${ }^{2}$ \\ 1 Companion Animal Clinic, School of Veterinary Medicine, Aristotle University of Thessaloniki, \\ 54627 Thessaloniki, Greece; kellypav@gmail.com \\ 2 Anaesthesiology and Perioperative Intensive Care Medicine, University of Veterinary Medicine, \\ 1210 Vienna, Austria; Christina.Braun@vetmeduni.ac.at (C.B.); yves.moens@vetmeduni.ac.at (Y.M.) \\ 3 Department of Large Animal Surgery, Anaesthesia and Orthopaedics, Faculty of Veterinary Medicine, \\ Ghent University, 9820 Merelbeke, Belgium; Stijn.Schauvliege@UGent.be \\ 4 Section of Veterinary Clinics and Animal Production, Department of Emergency and Organs Transplantation, \\ University of Bari Aldo Moro, 70010 Bari, Italy; francesco.staffieri@uniba.it \\ * Correspondence: isavas@vet.auth.gr
}

check for updates

Citation: Savvas, I.; Pavlidou, K.; Braun, C.; Schauvliege, S.; Staffieri, F; Moens, Y. Evaluation of the Effect of the Inspired Oxygen Fraction on Blood Oxygenation during Inhalant Anaesthesia in Horses: A Systematic Review with Meta-Analysis. Animals 2021, 11, 2245. https://doi.org/ 10.3390/ani11082245

Academic Editors:

Regula Bettschart-Wolfensberger,

Thijs van Loon and

Miguel Gozalo-Marcilla

Received: 21 June 2021

Accepted: 27 July 2021

Published: 30 July 2021

Publisher's Note: MDPI stays neutral with regard to jurisdictional claims in published maps and institutional affiliations.

Copyright: (c) 2021 by the authors. Licensee MDPI, Basel, Switzerland. This article is an open access article distributed under the terms and conditions of the Creative Commons Attribution (CC BY) license (https:// creativecommons.org/licenses/by/ $4.0 /)$.
Simple Summary: In anaesthetized horses, blood oxygenation impairment often occurs. This systematic review compared the effects of low and high inspired oxygen fractions on the arterial oxygen tension and other pulmonary gas exchange parameters in horses during inhalation anaesthesia. Five studies, four experimental and one clinical, were deemed suitable for inclusion. A meta-analysis was performed on the four experimental studies. The oxygen partial pressure was significantly lower with a lower inspired oxygen fraction. However, indices of pulmonary gas exchange were significantly worsened. It is concluded that, while only a limited number of studies are available, the use of a higher inspired oxygen fraction in horses during inhalation anaesthesia will result in higher levels of oxygen in the blood; it will also worsen the lung gas exchange status. Further studies are needed to increase the level of evidence on this subject.

Abstract: In anaesthetized horses, pronounced ventilation/perfusion mismatching often occurs. Several authors have investigated the effect of lower inspired oxygen fractions $\left(\mathrm{FIO}_{2}\right)$ to reduce formation of absorption atelectasis. This systematic review compared the effects of low $(<0.6)$ and high $(>0.8) \mathrm{FIO}_{2}$ on the arterial oxygen tension $\left(\mathrm{PaO}_{2}\right)$, the alveolar-to-arterial oxygen tension difference $\left(\mathrm{P}(\mathrm{A}-\mathrm{a}) \mathrm{O}_{2}\right)$, and the $\mathrm{PaO}_{2} / \mathrm{FIO}_{2}$ ratio in horses during inhalation anaesthesia. Using the Systematic Review Protocol for Animal Intervention Studies, four experimental and one clinical investigations were deemed suitable for inclusion. A meta-analysis was performed on the four experimental studies. The $\mathrm{PaO}_{2}$ was significantly lower $(p=0.0007$, mean difference $-23.54 \mathrm{kPa}$, $95 \% \mathrm{CI}-37.18,-9.90)$ with a lower $\mathrm{FIO}_{2}$. However, the $\mathrm{P}(\mathrm{A}-\mathrm{a}) \mathrm{O}_{2}$ was also significantly lower ( $p<0.00001$, mean difference $-20.80 \mathrm{kPa}, 95 \% \mathrm{CI}-26.28,-15.32)$ when using a low $\mathrm{FIO}_{2}$. For the $\mathrm{PaO}_{2} / \mathrm{FIO}_{2}$ ratio, only one study fitted the inclusion criteria, so no meta-analysis was performed. It is concluded that, while only a limited number of studies are available, the use of a higher $\mathrm{FIO}_{2}$ in horses during inhalation anaesthesia will result in higher levels of $\mathrm{PaO}_{2}$, but also a larger $\mathrm{P}(\mathrm{A}-\mathrm{a}) \mathrm{O}_{2}$ difference. Further studies are needed to increase the level of evidence on this subject.

Keywords: anaesthesia; blood oxygenation; horses

\section{Introduction}

Since almost sixty years ago, studies in humans have shown that during halothane anaesthesia with spontaneous breathing, ventilation/perfusion relationship (V/Q) abnormalities and intrapulmonary shunt may develop, resulting in a reduction in the arterial 
partial pressure of oxygen $\left(\mathrm{PaO}_{2}\right)$. One of the main causes of impaired oxygenation of the blood seems to be the development of atelectasis during anaesthesia, which reduces lung compliance and $\mathrm{PaO}_{2}$. There is supporting evidence that this condition may develop in humans, horses, and other animal species [1]. This was confirmed in computed tomography (CT) studies in humans, which revealed atelectasis of the most dependent parts of the lungs in $90 \%$ of the anaesthetised patients [2,3]. Development of atelectasis is considered to happen immediately after induction of anaesthesia [4,5]. Lung compression, gas absorption, and surfactant impairment are the major causative factors for atelectasis development [2].

Because of these reasons, it has been assumed that an alveolar partial pressure of oxygen $\left(\mathrm{PAO}_{2}\right)$ of at least $26.6 \mathrm{kPa}(200 \mathrm{mmHg})$ is needed in order to preserve normal $\mathrm{PaO}_{2}$ values [6-8]. However, higher levels of the fraction of inspired oxygen $\left(\mathrm{FIO}_{2}\right)$ will increase the rate of gas absorption from partially or completely occluded alveoli and produce atelectasis [2,6]. In fact, the use of $\mathrm{FIO}_{2} 1.0$ may even be the major causative factor for atelectasis development [4,9-12], since the composition of the inspired gas is directly related to the rate of the alveolar collapse of a completely closed lung unit.

In animals, lower $\mathrm{PaO}_{2}$ values have also been recorded in patients intraoperatively than in conscious subjects breathing the same $\mathrm{FIO}_{2}$. As in humans, a major factor for this is $\mathrm{V} / \mathrm{Q}$ alterations [1]. In horses, pronounced $\mathrm{V} / \mathrm{Q}$ abnormalities are commonly found, mainly caused by atelectasis formation in the dependent lung regions [13], a condition first published in an original and seminal paper on the subject, wherein it was shown that under halothane anaesthesia, a severe reduction in pulmonary ventilation may develop in horses [14]. However, the use of $\mathrm{FIO}_{2} 1.0$ to compensate for the atelectatic areas [15] may itself result in severe pulmonary atelectasis, creating a controversy among clinicians regarding the optimal $\mathrm{FIO}_{2}$.

Evidence from studies in animals (dog [16], cat [17], sheep [18], and horse [19-21]) indicate that the use of a low $\mathrm{FIO}_{2}$ may be beneficial in reducing lung atelectasis. On the other hand, there is evidence that $\mathrm{FIO}_{2} 0.3$ [22] or 0.5 [23] does not improve arterial oxygenation or gas exchange compared to $\mathrm{FIO}_{2}$ above 0.9. Some studies evaluate aeration based on the CT images of the lungs for atelectasis formation, while others investigate the oxygenation status of the animals.

Since there is lack of supporting evidence for the best $\mathrm{FIO}_{2}$ values intraoperatively in horses, we conducted this systematic review. The objective of our review was to systematically identify, appraise, and synthesise the evidence in relation to different $\mathrm{FIO}_{2}$ levels (high or low) in horses anaesthetised with inhalant anaesthetics. Specifically, our PICO question was: "Does a reduced $\mathrm{FIO}_{2}$ (below 0.6) compared to $\mathrm{FIO}_{2}$ above 0.8 improve blood oxygenation in horses during anaesthesia?".

\section{Methods}

A study protocol was established using the Systematic Review Protocol for Animal Intervention Studies (SYRCLE) [24].

\subsection{Type of Studies}

We included controlled studies on either experimental or client-owned animals, which compared at least two different $\mathrm{FIO}_{2}$ values during inhalant anaesthesia in horses. Reviews were excluded. Only publications in the English language were evaluated.

\subsection{Population/Species Studied}

The target species was the horse, of all ages. Only normocapnic patients were included.

\subsection{Interventions}

For the purpose of this review, a standard (control) treatment was defined as an $\mathrm{FIO}_{2}$ more than 0.8 and the intervention/exposure treatment as an $\mathrm{FIO}_{2}$ below 0.6. The mixture of inspired gas should contain medical air or nitrogen, but not other gases. 


\subsection{Outcome Measures}

- Arterial partial pressure of oxygen $\left(\mathrm{PaO}_{2}\right)$. All values were transformed to $\mathrm{kPa}$.

- Alveolar-arterial difference in the partial pressure of oxygen $\left(\mathrm{P}(\mathrm{A}-\mathrm{a}) \mathrm{O}_{2}\right)$. All values were transformed to $\mathrm{kPa}$.

- Arterial partial pressure of the oxygen to fraction of inspired oxygen ratio $\left(\mathrm{PaO}_{2} / \mathrm{FIO}_{2}\right)$.

\subsection{Search Method}

Four electronic databases were searched:

- MEDLINE via PubMed;

- Web of Science/CAB Abstracts;

- SCOPUS.

The search string was:

("oxygen") AND ("oxygenation" OR "atelectasis" OR "gas exchange" OR "oxygen ten-

sion" OR "pressure of oxygen" OR "Oxygen partial") AND (equine* OR horse*) AND

(anaest* OR anest*)

This string was adapted according to the search rules/code of the database used. All dates of publication were searched until end of May 2021.

\subsection{Selection of Studies}

Two groups, with two persons each (I.S. and K.P., and C.B. and S.S.), screened the results of the search output. Discrepancies were resolved with collaboration and critical discussion between the two groups. The first selection phase consisted of the evaluation of the title and abstract of the studies. The studies selected in this phase passed onto the second phase- the critical reading of the full paper. Whenever the authors of this review were also authors of an eligible study or had been a reviewer thereof, they were excluded from the evaluation.

\subsection{Data Extraction and Management}

Details of the eligible studies were independently extracted by the two groups of reviewers. Data extracted were:

- Authors, title, year of publication, and journal;

- Number of animals in intervention and control groups;

- Horses, age, weight, status ASA, inhalant agent, and spontaneous/mechanical ventilation;

- Outcome measures;

- Presence of any other outcome measures;

- Excluded animals (dropouts).

\subsection{Assessment of Risk of Bias in the Included Studies}

The two groups of reviewers assessed the included studies using the SYRCLE's Risk of Bias tool [25]. The following details were agreed on: When the study was randomised, but there was no mention of the randomisation method, we judged the study to have an unclear risk of bias. Random housing of the experimental animals was judged as low or unclear, as well as the animal assessors and animal selection blindness, because we assumed that these were mostly irrelevant to our review.

\subsection{Data Analysis}

Data were introduced into a specific software (Review Manager/RevMan Version 5.3. Copenhagen: The Nordic Cochrane Centre, The Cochrane Collaboration, 2014), where they were stored, analysed, and synthesised for the production of the meta-analysis. All three outcomes were continuous variables and were analysed with the inverse variance method with a random effects model. No subgroup analysis was performed (e.g., inhalant agent, and recumbency), because of the small number of the included studies. Effect measures 
are presented as the mean differences. Heterogeneity and overall effects were calculated. Statistical significance was set to $\alpha=0.05$.

\section{Results}

A total of 448 papers were retrieved. A PubMed search returned 135 results, Scopus 158, and Web of Science/CAB Abstracts 155. After removing the duplicates, 302 papers remained. The first selection phase revealed 19 papers eligible for further evaluation. The second selection phase revealed 5 papers, which were included in this review, and 14 papers were excluded (Figure 1).

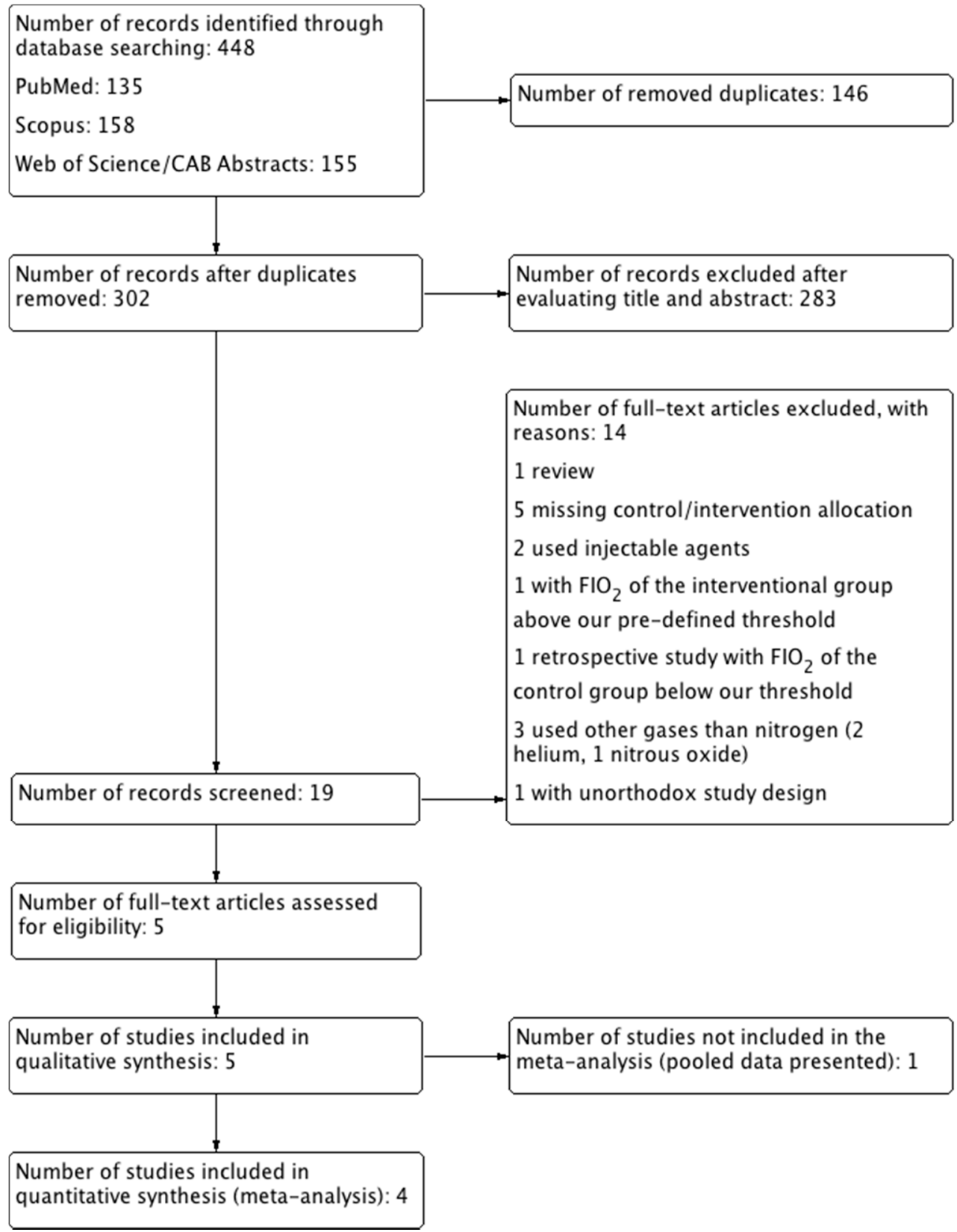

Figure 1. Study flow diagram.

\subsection{Characteristics of the Included Studies}

Four studies were experimental, and one study was a clinical trial. In the experimental studies, isoflurane was used to maintain anaesthesia in three studies (two with mechanical ventilation [23,26] and one with spontaneous ventilation [27]), and halothane in one (spon- 
taneous ventilation [19]). In the clinical trial, isoflurane was used for the maintenance of anaesthesia with mechanical ventilation [28] (Table 1).

Table 1. Characteristics of the five (5) included studies, by first author alphabetical order and year of publication.

\begin{tabular}{|c|c|c|c|c|c|c|c|}
\hline Reference & $\begin{array}{c}\text { Type of } \\
\text { Study/Design }\end{array}$ & $\begin{array}{l}\text { Animals } \\
\text { (Horses) }\end{array}$ & $\begin{array}{c}\text { Control/ } \\
\text { Intervention }\end{array}$ & Outcomes & Recumbency & $\begin{array}{l}\text { Maintenance } \\
\text { of Anaesthe- } \\
\text { sia/Type of } \\
\text { Ventilation }\end{array}$ & Notes \\
\hline $\begin{array}{c}\text { Crumley } 2013 \\
\text { [27] }\end{array}$ & $\begin{array}{l}\text { experimental/ } \\
\text { randomised } \\
\text { crossover }\end{array}$ & $\begin{array}{l}8 \text { (6 geldings, } \\
2 \text { mares), } \\
\text { median age } \\
10 \text { years), } \\
\text { median weight } \\
526 \mathrm{~kg}\end{array}$ & $\mathrm{FIO}_{2}>0.95 / 0.5$ & $\begin{array}{l}\text { haemodynamic } \\
\text { variables, } \\
\text { blood gas } \\
\text { analysis, } \\
\text { oxygen indices, } \\
\text { respiratory } \\
\text { parameters } \\
\text { haemodynamic }\end{array}$ & dorsal & $\begin{array}{l}\text { isoflurane (ET } \\
1.5 \% \text { )/sponta- } \\
\text { neous }\end{array}$ & $\begin{array}{c}\text { serial time } \\
\text { measurements, } \\
\text { data extracted } \\
\text { at } 90 \text { min } \\
\text { timepoint }\end{array}$ \\
\hline $\begin{array}{c}\text { Cuvelliez } 1990 \\
\text { [19] }\end{array}$ & $\begin{array}{l}\text { experimental/ } \\
\text { crossover }\end{array}$ & $\begin{array}{l}5 \text { ( } 2 \text { mares, } \\
3 \text { geldings), } \\
\text { various ages, } \\
\text { mean weight } \\
455 \pm 52 \mathrm{~kg}\end{array}$ & $\mathrm{FIO}_{2}>0.85 / 0.3$ & $\begin{array}{l}\text { variables, } \\
\text { blood gas } \\
\text { analysis, } \\
\text { oxygen } \\
\text { variables } \\
\text { calculation }\end{array}$ & left lateral & $\begin{array}{l}\text { halothane (ET } \\
1.2 \%) / \text { sponta- } \\
\text { neous }\end{array}$ & $\begin{array}{c}\text { serial time } \\
\text { measurements, } \\
\text { data extracted } \\
\text { at } 90 \text { min } \\
\text { timepoint }\end{array}$ \\
\hline $\begin{array}{c}\text { Hubbell } 2011 \\
\text { [23] }\end{array}$ & $\begin{array}{l}\text { experimental/ } \\
\text { randomised } \\
\text { crossover }\end{array}$ & $\begin{array}{l}5 \text { (2 geldings, } \\
3 \text { mares), } \\
\text { mature, mean } \\
\text { weight } 614 \text { kg }\end{array}$ & $\mathrm{FIO}_{2}>0.95 / 0.5$ & $\begin{array}{c}\text { haemodynamic } \\
\text { variables, } \\
\text { blood gas } \\
\text { analysis, } \\
\text { oxygen } \\
\text { variables } \\
\text { calculation }\end{array}$ & dorsal & $\begin{array}{l}\text { isoflurane (ET } \\
2 \% \text { )/mechani- } \\
\text { cal }\end{array}$ & $\begin{array}{l}\text { serial time } \\
\text { measurements, } \\
\text { data extracted } \\
\text { at } 90 \text { min } \\
\text { timepoint }\end{array}$ \\
\hline $\begin{array}{l}\text { Levionnois } \\
2016 \text { [28] }\end{array}$ & $\begin{array}{l}\text { clinical/ } \\
\text { prospective } \\
\text { randomised }\end{array}$ & $\begin{array}{l}\quad 40 \\
\text { warmbloods, } \\
\text { various ages } \\
\text { and weights }\end{array}$ & $\mathrm{FIO}_{2}>0.95 / 0.3$ & $\begin{array}{c}\text { haemodynamic } \\
\text { variables, } \\
\text { blood gases, } \\
\text { oxygen indices, } \\
\text { ventilatory } \\
\text { variables }\end{array}$ & $\begin{array}{l}19 \text { lateral, } \\
21 \text { dorsal }\end{array}$ & $\begin{array}{l}\text { isoflurane (ET } \\
1.2 \% \text { ) / mechan- } \\
\text { ical }\end{array}$ & $\begin{array}{c}\text { data collected } \\
\text { at } 3 \text { timepoints } \\
\text { in first hour, } \\
\text { pooled data are } \\
\text { presented, no } \\
\text { data extracted } \\
\text { for } \\
\text { meta-analysis }\end{array}$ \\
\hline $\begin{array}{c}\text { Portier } 2009 \\
{[26]}\end{array}$ & $\begin{array}{l}\text { experimental/ } \\
\text { randomised } \\
\text { crossover }\end{array}$ & $\begin{array}{l}6 \text { (geldings), } \\
\text { age } 4.5-9.5 \\
\text { years, weight } \\
510-640 \mathrm{~kg}\end{array}$ & $\mathrm{FIO}_{2} 1.0 / 0.21$ & $\begin{array}{c}\text { haemodynamic } \\
\text { variables, } \\
\text { blood gas } \\
\text { analysis, } \\
\text { oxygen } \\
\text { variables } \\
\text { calculation }\end{array}$ & left lateral & $\begin{array}{l}\text { isoflurane, } \\
\text { mechanical }\end{array}$ & $\begin{array}{c}\text { serial time } \\
\text { measurements, } \\
\text { data extracted } \\
\text { at } 90 \text { min } \\
\text { timepoint }\end{array}$ \\
\hline
\end{tabular}

ET: end-tidal.

All the experimental studies had a crossover design, with 5-8 horses included in each one. Three were adequately randomised, but one had an unclear risk of randomisation bias [19]. The clinical study was a prospective randomised one. Outcome measures were serially (over time of anaesthesia) recorded in all studies. We collected and analysed data for the meta-analysis at the 90 min timepoint from all the experimental studies, which was the commonest timepoint among the studies. In the clinical study [28], data had been recorded at three timepoints during anaesthesia, and the pooled data are presented in the paper; therefore, the data were extracted for the qualitative analysis, but were not used for the meta-analysis.

In all studies, the standard treatment was an $\mathrm{FIO}_{2}$ above 0.85. Intervention treatment was an $\mathrm{FIO}_{2}$ of 0.5 in two experimental studies. In the other three studies, the intervention groups received an $\mathrm{FIO}_{2}$ of 0.21 (experimental study) and 0.3 (one experimental and one clinical).

In only one study [28] an a priori power analysis was performed, however the post hoc power of the study was poor. 


\subsection{Risk of Bias of the Included Studies}

The risk of bias was found to be unclear or low in most of the studies. The risk of bias tables are shown in Figures 2 and 3.

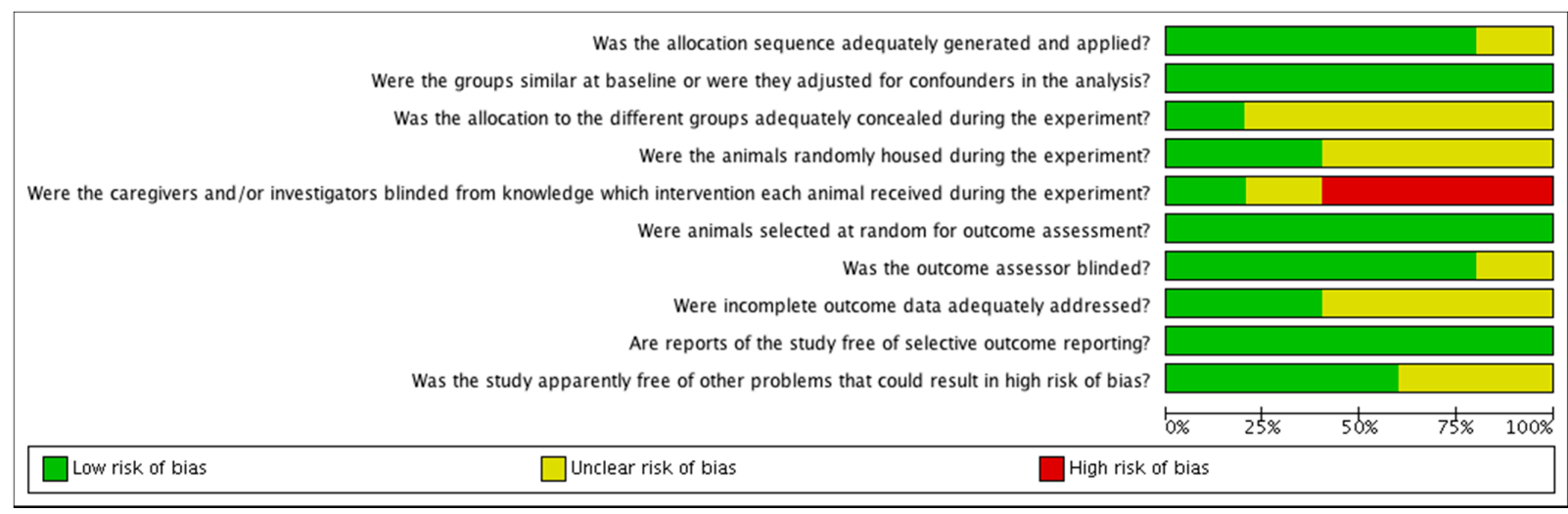

Figure 2. Risk of bias graph: review authors' judgements about each risk of bias item presented as percentages across all included studies.

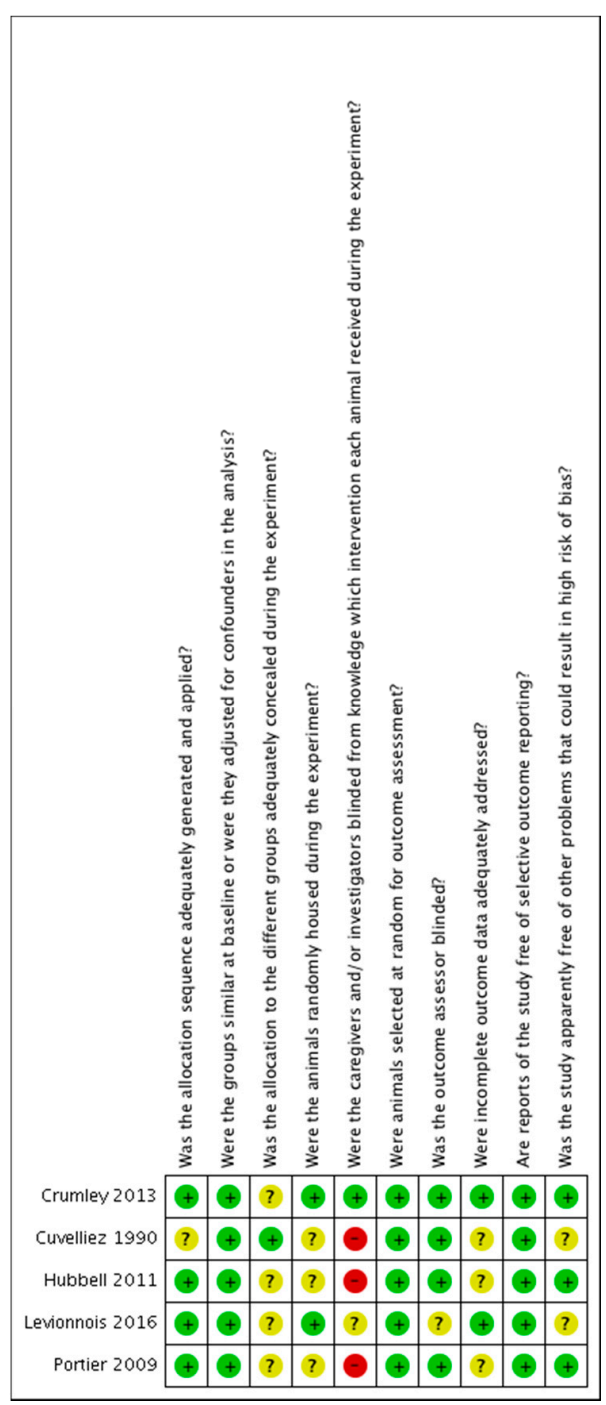

Figure 3. Risk of bias summary: review authors' judgements about each risk of bias item for each included study. ?: unclear risk; -: high risk; +: low risk. 


\subsection{Characteristics of the Excluded Studies}

Fourteen studies were excluded after critically evaluating them: one review [29]; five due to missing control/intervention allocation of the animals [30-34]; two studies [20,35] because injectable agents were used for the maintenance of anaesthesia; one with an $\mathrm{FIO}_{2}$ of the interventional group above our pre-defined threshold of 0.6 [36]; and one retrospective study with an average $\mathrm{FIO}_{2}$ of the control group below our threshold of 0.8 [37]. Furthermore, three more studies were excluded as other gases than nitrogen were used to decrease the $\mathrm{FIO}_{2}$ : in two studies [21,38] the intervention group received a mixture of oxygen with helium, and in one study [39] the inspired mixture consisted of oxygen and nitrous oxide. Finally, one study [40] had an unorthodox study design: 24 animals were used to compare the influence of a delivered oxygen fraction $\left(\mathrm{FdO}_{2}\right)$ of 1.0 and 0.6 during isoflurane anaesthesia. Sixteen horses underwent an arthroscopy in dorsal recumbency and were equally and randomly allocated over the two treatments, while the remaining eight horses received both treatments in a randomized crossover study in lateral recumbency for a wound healing study. The main reason for exclusion of this study is that the authors targeted a fixed $\mathrm{FdO}_{2}$, which may have resulted in some variability of the $\mathrm{FIO}_{2}$ among individual horses, although a similar influence would be expected with both treatments.

\subsection{The Effect of Low $\mathrm{FIO}_{2}$ on $\mathrm{PaO}_{2}$}

Data for the $\mathrm{FIO}_{2}$ were extracted from all five studies; in all of them, a low $\mathrm{FIO}_{2}$ statistically significantly reduced the $\mathrm{PaO}_{2}$ of the horses. Four studies were included in the meta-analysis (Figure 4). Data from a total of 24 animals were analysed. The heterogeneity of the studies was statistically significant $\left(p<0.00001, \mathrm{I}^{2}=99 \%\right)$ and the overall effect was statistically significant $(p=0.0007$, mean difference $=-23.54,95 \%$ CI $-37.18,-9.90)$, in favour of the high $\mathrm{FIO}_{2}$.

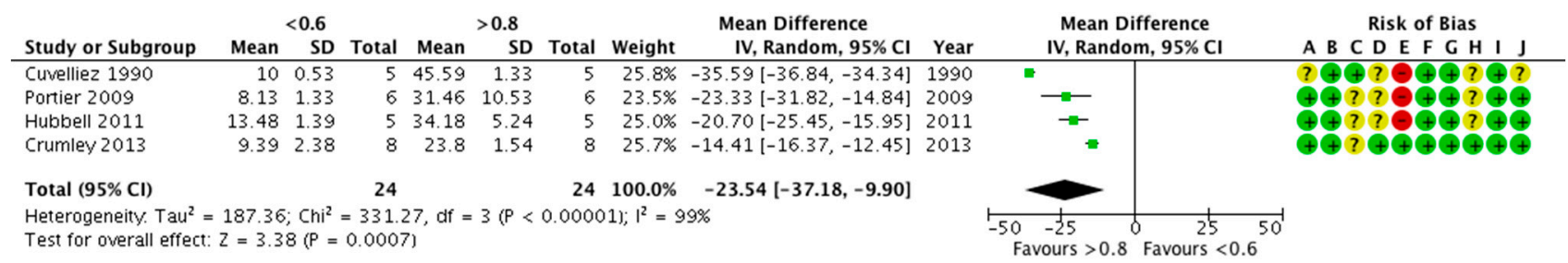

Risk of bias legend

(A) Was the allocation sequence adequately generated and applied?

(B) Were the groups similar at baseline or were they adjusted for confounders in the analysis?

(C) Was the allocation to the different groups adequately concealed during the experiment?

(D) Were the animals randomly housed during the experiment?

(E) Were the caregivers and/or investigators blinded from knowledge which intervention each animal received during the experiment?

(F) Were animals selected at random for outcome assessment?

(G) Was the outcome assessor blinded?

(H) Were incomplete outcome data adequately addressed?

(I) Are reports of the study free of selective outcome reporting?

(J) Was the study apparently free of other problems that could result in high risk of bias?

Figure 4. Forest plot of the effect of the $\mathrm{FIO}_{2}$ on $\mathrm{PaO}_{2}$. Units are in $\mathrm{kPa}$. CI: confidence interval; IV: inverse variance; SD: standard deviation. ?: unclear risk; -: high risk; +: low risk.

Because of the high heterogeneity, a sensitivity analysis was also performed, by removing each study from the model. By removing the studies of Portier et al. (2009), Hubbell et al. (2011), or Crumley et al. (2013), there was a minor change in the $\mathrm{I}^{2}$ and the $p$-values. However, when removing the Cuvelliez et al. (1990) study, the $\mathrm{I}^{2}$ was reduced to $78 \%$ (still significant, $p=0.01$ ), with an overall effect again statistically significant $(p<0.00001$, mean difference $=-18.58,95 \% \mathrm{CI}-24.26,-12.91)$, in favour of the high $\mathrm{FIO}_{2}$ (19 animals in the model). It seems that the Cuvelliez et al. (1990) study is the major source of heterogeneity; as can be seen, it has the largest mean difference between the two groups. 


\subsection{The Effect of Low $\mathrm{FIO}_{2}$ on $\mathrm{P}(\mathrm{A}-a) \mathrm{O}_{2}$}

Data of $\mathrm{P}(\mathrm{A}-\mathrm{a}) \mathrm{O}_{2}$ measurements were found in four studies. In one study [28], there was a statistically non-significant difference between the control and the intervention groups, regarding the $\mathrm{P}(\mathrm{A}-\mathrm{a}) \mathrm{O}_{2}$, but these data were not included in the meta-analysis, because they were pooled out of several timepoints. In the remaining three studies, the low $\mathrm{FIO}_{2}$ statistically significantly reduced the $\mathrm{P}(\mathrm{A}-\mathrm{a}) \mathrm{O}_{2}$ (Figure 5). Data from a total of 18 animals were analysed. The heterogeneity of the studies was statistically non-significant $\left(p<0.1, \mathrm{I}^{2}=57 \%\right)$ and the overall effect was statistically significant $(p<0.00001$, mean difference $=-20.80,95 \% \mathrm{CI}(-26.28,-15.32))$, in favour of the low $\mathrm{FIO}_{2}$.

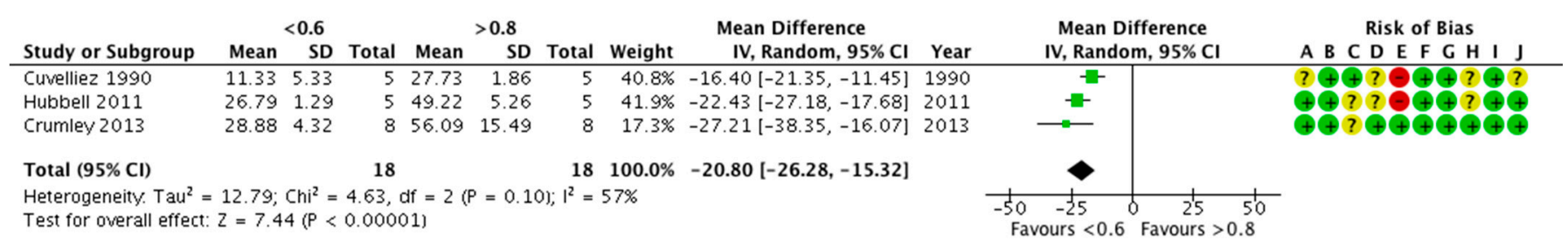

Risk of bias legend

(A) Was the allocation sequence adequately generated and applied?

(B) Were the groups similar at baseline or were they adjusted for confounders in the analysis?

(C) Was the allocation to the different groups adequately concealed during the experiment?

(D) Were the animals randomly housed during the experiment?

(E) Were the caregivers and/or investigators blinded from knowledge which intervention each animal received during the experiment?

(F) Were animals selected at random for outcome assessment?

(G) Was the outcome assessor blinded?

(H) Were incomplete outcome data adequately addressed?

(I) Are reports of the study free of selective outcome reporting?

(J) Was the study apparently free of other problems that could result in high risk of bias?

Figure 5. Forest plot of the effect of $\mathrm{FIO}_{2}$ on $\mathrm{P}(\mathrm{A}-\mathrm{a}) \mathrm{O}_{2}$. Units are in $\mathrm{kPa}$. CI: confidence interval; IV: inverse variance; SD: standard deviation. ?: unclear risk; -: high risk; +: low risk.

\subsection{The Effect of Low $\mathrm{FIO}_{2}$ on $\mathrm{PaO}_{2} / \mathrm{FIO}_{2}$}

Data on $\mathrm{PaO}_{2} / \mathrm{FIO}_{2}$ measurements were found in two studies. In one study [28], there was a non-significant difference in $\mathrm{PaO}_{2} / \mathrm{FIO}_{2}$; however, these data were not used for the meta-analysis, because they were pooled out of several timepoints. In the other study [23], the low $\mathrm{FIO}_{2}$ statistically significantly reduced the $\mathrm{PaO}_{2} / \mathrm{FIO}_{2}$. No meta-analysis was produced for this outcome.

\section{Discussion}

According to our knowledge, this is the first systematic review with a meta-analysis to evaluate the effect of the inspired oxygen fraction on the oxygenation of the blood in anaesthetised horses. This review combined the results of five studies, four experimental and one clinical (not used in the meta-analysis), including a total of 64 horses (24 in the meta-analysis). It is interesting that very few clinical studies were found, although we believe that the extent of the use of low $\mathrm{FIO}_{2}$ mixtures in clinical practice is higher than depicted in the published literature; an indication is given in a retrospective study [37]. In an attempt to have more meaningful results, we excluded studies with injectable agents, because the effect of the different injectable anaesthetic drugs on the respiratory system and the pulmonary function is diverse.

Moreover, we excluded studies where the inspired gas mixture consisted of gas other than oxygen with medical air or nitrogen. For instance, we excluded two studies with helium in the inspired mixture [21,38], because of the specific physical properties of helium. Interestingly, in both studies, $\mathrm{PaO}_{2}$ and $\mathrm{P}(\mathrm{A}-\mathrm{a}) \mathrm{O}_{2}$ were higher $\left(\mathrm{P}(\mathrm{A}-\mathrm{a}) \mathrm{O}_{2}\right.$ (non-significantly in [38]) with a high $\mathrm{FIO}_{2}$, whereas the $\mathrm{PaO}_{2} / \mathrm{FIO}_{2}$ ratio was lower. Moreover, we excluded another study [39] with $\mathrm{N}_{2} \mathrm{O}$ in the mixture, an agent with special anaesthetic and analgesic properties, which may have affected pulmonary function. In this study, $\mathrm{PaO}_{2}$ was also higher in high $\mathrm{FIO}_{2}$. Although we have not included these three studies in our review, we assume that this has not substantially affected our results. 
A variety of factors, e.g., breed, gender, age, type of ventilation, application of positive end-expiratory pressure, tidal volume used, etc. [1], as well as body position, body weight, and thoracic conformation [41,42] may affect the oxygenation of the blood. Because of the diversity of the equine population recruited in these studies, we assumed that the heterogeneity of the studies was high, and it was treated as such in the meta-analysis (random effect analysis was used). That was also the reason why a subgroup analysis was not performed.

As an appraisal method to estimate bias, we used the SYRCLE's risk of bias tool for animal studies, which is an adapted version of the Cochrane risk of bias tool. Although it is not fully validated, it takes into account the specific aspects of the experimental design of animal studies compared to clinical studies [25]. In our review, we have included experimental as well as randomised clinical animal studies, so we believe that the choice of the SYRCLE's risk of bias tool was the best available option.

From this review, it is clear that the arterial partial pressure of the oxygen is higher when a high oxygen fraction is inhaled, which is an expected result, especially when mechanical ventilation is applied. However, this is not the only index of oxygen exchange. The horse may not be hypoxic, although severe intrapulmonary V/Q mismatch may develop intraoperatively, and lead to increased mortality post-operatively [15]. Furthermore, in practice, as long as the $\mathrm{PaO}_{2}$ is in the range to fully saturate haemoglobin, differences in $\mathrm{PaO}_{2}$ have limited relevance. It may, e.g., be more useful to study the influence of the $\mathrm{FIO}_{2}$ on the incidence of hypoxaemia. Other indices are also used to assess pulmonary gas exchange. $\mathrm{P}(\mathrm{A}-\mathrm{a}) \mathrm{O}_{2}$ is an index of intrapulmonary shunt or $\mathrm{V} / \mathrm{Q}$ scatter, although it can be affected by $\mathrm{PAO}_{2}$, cardiac output, body temperature, $\mathrm{pH}$ and base excess of the blood, haemoglobin concentration, and alveolar ventilation [7]. This review revealed that the alveolar-arterial difference is higher in high fractions of inspired oxygen, an indication of compromised pulmonary function. Unfortunately, there is very limited information of the effect of high inspired oxygen on another index, the $\mathrm{PaO}_{2} / \mathrm{FIO}_{2}$ ratio. It would be interesting to have data of this outcome measure, since it has been shown in humans that the $\mathrm{PaO}_{2} / \mathrm{FIO}_{2}$ ratio, as well as the $\mathrm{P}(\mathrm{A}-\mathrm{a}) \mathrm{O}_{2}$ difference, depends on $\mathrm{FIO}_{2}$ [43], whereas in sheep, the $\mathrm{P}(\mathrm{A}-\mathrm{a}) \mathrm{O}_{2}$ difference correlation to shunt seems to be weaker than that of the $\mathrm{PaO}_{2} / \mathrm{FIO}_{2}$ ratio [44].

Another technique to detect the matching between alveolar ventilation and pulmonary blood perfusion is the multiple inert gas elimination technique (MIGET), which uses six (usually) inert gases $[45,46]$. One study [20] using this technique in horses was found during our literature search. This study shows an increased intrapulmonary shunt when high $\mathrm{FIO}_{2}$ is administered, despite the high $\mathrm{PaO}_{2}$ measured. This shunt persisted into recovery. These results support the findings of this review, although unfortunately we could not include this study in the systematic review and meta-analysis, because this experimental study used dissociative anaesthesia, and also did not calculate the indices we were looking for.

It is known that the alveolar $\mathrm{O}_{2}$ concentration affects the development of absorption atelectasis; however, in horses, compression of the lungs because of the shape and the position of the diaphragmatic dome, in combination with a high pressure exerted by the abdominal contents (especially in dorsal recumbency), may promote compression atelectasis. Thus, lowering the $\mathrm{FIO}_{2}$ may not be the only intervention to improve oxygenation, and other strategies, e.g., alveolar recruiting strategies, may be more effective in improving oxygenation.

Our review possesses some limitations. The first one is the small number of included studies and animal population. It seems that very few studies have been performed on that topic, and the ones available often differ substantially in their methodology and described outcome, making it questionable to combine their results. Thus, this systematic review is accompanied by a meta-analysis with a fairly limited number of studies. While limited data as well as high heterogeneity are reasons to avoid a meta-analysis, there is no agreement on a cut off regarding these factors [47]. In our opinion, the meta-analysis 
serves as an additional aid to evaluate the presented information in a concise fashion. Certainly, there is a need for more research in this area, because equine intraoperative hypoxia is a serious problem in clinical practice. The second limitation is that the subgroup analysis was not possible for any comparison. Future well-designed experimental studies and clinical trials using targeted evaluating tools are necessary to increase the level of evidence, for better decision making. The third limitation (although not an inherent one of our review, rather than a limitation of the included studies) is the lack of power analysis in the included studies, which may have compromised the level of evidence. Having in mind these limitations, and despite a clear trend towards specific results, the findings of this review should be interpreted cautiously.

\section{Conclusions}

Considering a low to medium level of evidence, the reduction of $\mathrm{FIO}_{2}$ in horses under anaesthesia may improve some oxygenation indices, e.g., shunt, but will decrease blood oxygenation.

Author Contributions: Conceptualization, I.S. and K.P.; methodology, I.S., K.P., C.B. and S.S.; formal analysis, I.S., K.P., C.B. and S.S.; supervision, I.S.; reviewing, Y.M. and F.S. All authors have read and agreed to the published version of the manuscript.

Funding: This research received no external funding.

Institutional Review Board Statement: Not applicable.

Informed Consent Statement: Not applicable.

Data Availability Statement: Data is contained within the article.

Conflicts of Interest: The authors declare no conflict of interest.

\section{References}

1. McDonell, W.N.; Kerr, C.L. Physiology, Pathophysiology, and Anesthetic Management of Patients with Respiratory Disease. In Veterinary Anesthesia and Analgesia; Grimm, K.A., Lamont, L.A., Tranquilli, W.J., Greene, S.A., Robertson, S.A., Eds.; John Wiley \& Sons: Hoboken, NJ, USA, 2015; pp. 513-555, ISBN 1118526201.

2. Magnusson, L.; Spahn, D.R. New concepts of atelectasis during general anaesthesia. Br. J. Anaesth. 2003, 91, 61-72. [CrossRef] [PubMed]

3. Lundquist, H.; Hedenstierna, G.; Strandberg, A.; Tokics, L.; Brismar, B. CT-Assessment of Dependent Lung Densities in Man During General Anaesthesia. Acta Radiol. 1995, 36, 626-632. [CrossRef]

4. Brismar, B.; Hedenstierna, G.; Lundquist, H.; Strandberg, A.; Svensson, L.; Tokics, L. Pulmonary densities during anesthesia with muscular relaxation-a proposal of atelectasis. Anesthesiology 1985, 62, 422-428. [CrossRef] [PubMed]

5. Strandberg, A.; Tokics, L.; Brismar, B.; Lundquist, H.; Hedenstierna, G. Atelectasis during anaesthesia and in the postoperative period. Acta Anaesthesiol. Scand. 1986, 30, 154-158. [CrossRef] [PubMed]

6. Duggan, M.; Kavanagh, B.P. Pulmonary atelectasis: A pathogenic perioperative entity. Anesthesiology 2005, 102, 838-854. [CrossRef] [PubMed]

7. Lumb, A.B. Anaesthesia. In Nunn's Applied Respiratory Physiology; Lumb, A.B., Ed.; Churchill Livingston Elsevier: Edinburgh, UK, 2010; pp. 327-354.

8. Nunn, J.F. Factors Influencing the Arterial Oxygen Tension During Halothane Anaesthesia with Spontaneous Respiration. Br. J. Anaesth. 1964, 36, 327-341. [CrossRef] [PubMed]

9. Edmark, L.; Kostova-Aherdan, K.; Enlund, M.; Hedenstierna, G. Optimal oxygen concentration during induction of general anesthesia. Anesthesiology 2003, 98, 28-33. [CrossRef]

10. Rothen, H.U.; Sporre, B.; Engberg, G.; Wegenius, G.; Reber, A.; Hedenstierna, G. Prevention of atelectasis during general anaesthesia. Lancet 1995, 345, 1387-1391. [CrossRef]

11. Gunnarsson, L.; Tokics, L.; Gustavsson, H.; Hedenstierna, G. Influence of age on atelectasis formation and gas exchange impairment during general anaesthesia. Br. J. Anaesth. 1991, 66, 423-432. [CrossRef] [PubMed]

12. Rothen, H.U.; Sporre, B.; Engberg, G.; Wegenius, G.; Hedenstierna, G. Re-expansion of atelectasis during general anaesthesia: A computed tomography study. Br. J. Anaesth. 1993, 71, 788-795. [CrossRef]

13. Nyman, G.; Funkquist, B.; Kvart, C.; Frostell, C.; Tokics, L.; Strandberg, A.; Lundquist, H.; Lundh, B.; Brismar, B.; Hedenstierna, G. Atelectasis causes gas exchange impairment in the anaesthetised horse. Equine Vet. J. 1990, 22, 317-324. [CrossRef]

14. Hall, L.W.; Gillespie, J.R.; Tyler, W.S. Alveolar-arterial oxygen tension differences in anaesthetized horses. Br. J. Anaesth. 1968, 40, 560-568. [CrossRef] 
15. Kerr, C.L.; McDonell, W.N. Oxygen Supplementation and Ventilatory Support. In Equine Anesthesia Monitoring and Emergency Therapy; Muir, W.W., Hubbell, J.A.E., Eds.; Saunders Elsevier: St. Louis, MO, USA, 2009; pp. 332-352.

16. Staffieri, F.; Franchini, D.; Carella, G.L.; Montanaro, M.G.; Valentini, V.; Driessen, B.; Grasso, S.; Crovace, A. Computed tomographic analysis of the effects of two inspired oxygen concentrations on pulmonary aeration in anesthetized and mechanically ventilated dogs. Am. J. Vet. Res. 2007, 68, 925-931. [CrossRef]

17. Staffieri, F.; De Monte, V.; De Marzo, C.; Grasso, S.; Crovace, A. Effects of two fractions of inspired oxygen on lung aeration and gas exchange in cats under inhalant anaesthesia. Vet. Anaesth. Analg. 2010, 37, 483-490. [CrossRef]

18. Staffieri, F.; Driessen, B.; De Monte, V.; Grasso, S.; Crovace, A. Effects of positive end-expiratory pressure on anesthesia-induced atelectasis and gas exchange in anesthetized and mechanically ventilated sheep. Am. J. Vet. Res. 2010, 71, 867-874. [CrossRef] [PubMed]

19. Cuvelliez, S.G.; Eicker, S.W.; McLauchlan, C.; Brunson, D.B. Cardiovascular and respiratory effects of inspired oxygen fraction in halothane-anesthetized horses. Am. J. Vet. Res. 1990, 51, 1226-1231. [PubMed]

20. Marntell, S.; Nyman, G.G.G.; Hedenstierna, G.G.G. High inspired oxygen concentrations increase intrapulmonary shunt in anaesthetized horses. Vet. Anaesth. Analg. 2005, 32, 338-347. [CrossRef]

21. Staffieri, F.; Bauquier, S.H.; Moate, P.J.; Driessen, B. Pulmonary gas exchange in anaesthetised horses mechanically ventilated with oxygen or a helium/oxygen mixture. Equine Vet. J. 2009, 41, 747-752. [CrossRef] [PubMed]

22. Levionnois, O.L.; Kuich, N. Lower intra-operative oxygen inspiration fraction do not improve arterial oxygenation after isoflurane anaesthesia with mechanical ventilation in clinical horses. In Proceedings of the AVA Autumn Meeting, Barcelona, Spain, 14-16 October 2008; pp. 60-61.

23. Hubbell, J.A.; Aarnes, T.K.; Bednarski, R.M.; Lerche, P.; Muir, W.W. Effect of 50\% and maximal inspired oxygen concentrations on respiratory variables in isoflurane-anesthetized horses. BMC Vet. Res. 2011, 7, 23. [CrossRef]

24. de Vries, R.B.M.; Hooijmans, C.R.; Langendam, M.W.; van Luijk, J.; Leenaars, M.; Ritskes-Hoitinga, M.; Wever, K.E. A protocol format for the preparation, registration and publication of systematic reviews of animal intervention studies. Evidence Based Preclin. Med. 2015, 2, e00007. [CrossRef]

25. Hooijmans, C.R.; Rovers, M.M.; de Vries, R.B.; Leenaars, M.; Ritskes-Hoitinga, M.; Langendam, M.W. SYRCLE's risk of bias tool for animal studies. BMC Med. Res. Methodol. 2014, 14, 43. [CrossRef] [PubMed]

26. Portier, K.; Crouzier, D.; Guichardant, M.; Prost, M.; Debouzy, J.-C.; Kirschvink, N.; Fellmann, N.; Lekeux, P.; Coudert, J. Effects of high and low inspired fractions of oxygen on horse erythrocyte membrane properties, blood viscosity and muscle oxygenation during anaesthesia. Vet. Anaesth. Analg. 2009, 36, 287-298. [CrossRef] [PubMed]

27. Crumley, M.N.; McMurphy, R.M.; Hodgson, D.S.; Kreider, S.E. Effects of inspired oxygen concentration on ventilation, ventilatory rhythm, and gas exchange in isoflurane-anesthetized horses. Am. J. Vet. Res. 2013, 74, 183-190. [CrossRef] [PubMed]

28. Levionnois, O.L.; Zuehlke, N.; Kuhn, M.; Spadavecchia, C. Impact of low inspired oxygen fraction on oxygenation in clinical horses under general anesthesia. Pferdeheilkd. Equine Med. 2016, 32, 461-468. [CrossRef]

29. Auckburally, A.; Nyman, G.G.G. Review of hypoxaemia in anaesthetized horses: Predisposing factors, consequences and management. Vet. Anaesth. Analg. 2017, 44, 397-408. [CrossRef]

30. Briganti, A.; Portela, D.A.; Grasso, S.; Sgorbini, M.; Tayari, H.; Bassini, J.R.F.F.; Vitale, V.; Romano, M.S.; Crovace, A.; Breghi, G.; et al. Accuracy of different oxygenation indices in estimating intrapulmonary shunting at increasing infusion rates of dobutamine in horses under general anaesthesia. Vet. J. 2015, 204, 351-356. [CrossRef]

31. de Moor, A.; van den Hende, C. Inspiratory Concentrations of $\mathrm{O}_{2}, \mathrm{~N}_{2}$ and $\mathrm{N}_{2} \mathrm{O}$, Arterial Oxygenation and Acid-Base Status during Closed System Halothane Anaesthesia in the Horse. Zent. Veterinärmedizin R. A 1972, 19, 1-7. [CrossRef]

32. Pakkanen, S.A.; Raekallio, M.R.; Mykkänen, A.K.; Salla, K.M.; de Vries, A.; Vuorilehto, L.; Scheinin, M.; Vainio, O.M. Detomidine and the combination of detomidine and MK-467, a peripheral alpha-2 adrenoceptor antagonist, as premedication in horses anaesthetized with isoflurane. Vet. Anaesth. Analg. 2015, 42, 527-536. [CrossRef]

33. Young, L.E.; Marlin, D.J.; McMurphy, R.M.; Walsh, K.; Dixon, P.M. Effects of inhaled nitric oxide 10 ppm in spontaneously breathing horses anaesthetized with halothane. Br. J. Anaesth. 1999, 83, 321-324. [CrossRef]

34. Nyman, G.; Frostell, C.; Hedenstierna, G.; Funkquist, B.; Kvart, C.; Blomqvist, H. Selective mechanical ventilation of dependent lung regions in the anaesthetized horses in dorsal recumbency. Br. J. Anaesth. 1987, 59, 1027-1034. [CrossRef]

35. Karrasch, N.M.; Hubbell, J.A.E.; Aarnes, T.K.; Bednarski, R.M.; Lerche, P. Comparison of cardiorespiratory variables in dorsally recumbent horses anesthetized with guaifenesin-ketamine-xylazine spontaneously breathing $50 \%$ or maximal oxygen concentrations. Can. Vet. J. 2015, 56, 387-392.

36. Taylor, A.H.; Seymour, C.J. Effect of low inspired oxygen fraction on respiratory indices in mechanically ventilated horses anaesthetised with isoflurane and medetomidine constant rate infusion. Vet. J. 2016, 211, 70-74. [CrossRef]

37. Schauvliege, S.; Savvas, I.; Gasthuys, F. The effect of the inspired oxygen fraction on arterial blood oxygenation in spontaneously breathing, isoflurane anaesthetized horses: A retrospective study. Vet. Anaesth. Analg. 2015, 42, 280-285. [CrossRef] [PubMed]

38. Hopster, K.; Duffee, L.R.; Hopster-Iversen, C.C.S.S.; Driessen, B. Efficacy of an alveolar recruitment maneuver for improving gas exchange and pulmonary mechanics in anesthetized horses ventilated with oxygen or a helium-oxygen mixture. Am. J. Vet. Res. 2018, 79, 1021-1027. [CrossRef] [PubMed] 
39. Young, L.E.; Richards, D.L.S.; Brearley, J.C.; Bartram, D.H.; Jones, R.S. The effect of a 50\% inspired mixture of nitrous oxide on arterial oxygen tension in spontaneously breathing horses anaesthetised with halothane. Vet. Anaesth. Analg. 1992, 19, 37-40. [CrossRef]

40. Uquillas, E.; Dart, C.; Perkins, N.; Dart, A. Effect of reducing inspired oxygen concentration on oxygenation parameters during general anaesthesia in horses in lateral or dorsal recumbency. Aust. Vet. J. 2018, 96, 46-53. [CrossRef]

41. Moens, Y.; Lagerweij, E.; Gootjes, P.; Poortman, J. Distribution of inspired gas to each lung in the anaesthetised horse and influence of body shape. Equine Vet. J. 1995, 27, 110-116. [CrossRef]

42. Mansel, J.C.; Clutton, R.E. The influence of body mass and thoracic dimensions on arterial oxygenation in anaesthetized horses and ponies. Vet. Anaesth. Analg. 2008, 35, 392-399. [CrossRef] [PubMed]

43. Karbing, D.S.; Kjærgaard, S.; Smith, B.W.; Espersen, K.; Allerød, C.; Andreassen, S.; Rees, S.E. Variation in the $\mathrm{PaO}_{2} / \mathrm{FiO}_{2}$ ratio with $\mathrm{FiO}_{2}$ : Mathematical and experimental description, and clinical relevance. Crit. Care 2007, 11, R118. [CrossRef]

44. Araos, J.D.; Larenza, M.P.; Boston, R.C.; De Monte, V.; De Marzo, C.; Grasso, S.; Haskins, S.C.; Crovace, A.; Staffieri, F. Use of the oxygen content-based index, Fshunt, as an indicator of pulmonary venous admixture at various inspired oxygen fractions in anesthetized sheep. Am. J. Vet. Res. 2012, 73, 2013-2020. [CrossRef] [PubMed]

45. Mélot, C. Contribution of multiple inert gas elimination technique to pulmonary medicine. 5. Ventilation-perfusion relationships in acute respiratory failure. Thorax 1994, 49, 1251-1258. [CrossRef] [PubMed]

46. Roca, J.; Wagner, P.D. Contribution of multiple inert gas elimination technique to pulmonary medicine. 1. Principles and information content of the multiple inert gas elimination technique. Thorax 1994, 49, 815-824. [CrossRef] [PubMed]

47. Ioannidis, J.P.A.; Patsopoulos, N.A.; Rothstein, H.R. Reasons or excuses for avoiding meta-analysis in forest plots. Br. Med. J. 2008, 336, 1413-1415. [CrossRef] [PubMed] 